\title{
Description of Micropygomyia (Micropygomyia) ancashensis sp. nov. and the female of Lutzomyia (Helcocyrtomyia) chavinensis Pérez \& Ogusuku (Diptera, Psychodidae, Phlebotominae) from Ancash department, Peru
}

\author{
Eunice A Bianchi Galati/ ${ }^{+}$, Abraham G Cáceres*
}

\begin{abstract}
Departamento de Epidemiologia, Faculdade de Saúde Pública, Universidade de São Paulo, Av. Dr. Arnaldo 715, 01246-904 São Paulo, SP, Brasil *Sección de Entomología, Instituto de Medicina Tropical “Daniel A. Carrión”, Universidad Nacional Mayor de San Marcos and Laboratorio de Entomología, Instituto Nacional de Salud, Lima, Perú
\end{abstract}

A male of a new species Micropygomyia (Micropygomyia) ancashensis sp. nov. and a female of the Lutzomyia (Helcocyrtomyia) chavinensis Pérez \& Ogusuku, 1999 captured in the Antonio Raymondi province, department of Ancash, Peru are described and illustrated. The new species belongs to the cayennensis series, being closest to Mi. lewisi (Feliciangeli Ordoñez \& Férnandez) though presenting highly sclerotized pseudotracheae on the labella that seem to constitute an autapomorphy among American Phlebotominae, and a clypeus almost completely covered with setae, as in Warileya. The female of Lu. chavinensis is close to those of Lu. blancasi Galati \& Cáceres 1990, Lu. noguchii (Shannon, 1929), and Lu. pallidithorax Galati \& Cáceres 1994.

Key words: description - Lutzomyia (Helcocyrtomyia) chavinensis - Micropygomyia (Micropygomyia) ancashensis sp. nov. Phlebotominae, Pyschodidae - taxonomy.

A male of a new species of Micropygomyia (Micropygomyia) was captured during entomological studies undertaken in 1999 in the Antonio Raymondi province, department of Ancash, Peru. Together with this specimen, two males of Lutzomyia (Helcocyrtomyia) chavinensis Pérez \& Ogusuku, 1999 and one female which has not hitherto been described and that we presume to belong to this same species were also found.

Micropygomyia Barretto, 1962, proposed as subgenus of Lutzomyia França, 1924, was raised to genus level of Brumptomyiina by Artemiev (1991), with the inclusion of the three subgenera: Micropygomyia, s. str., Sciopemyia Barretto, 1962, and Sauromyia Artemiev, 1991. Galati (1995, 2003a) included Micropygomyia in Sergentomyiina, and divided the genus into four subgenera: Silvamyia Galati 1995, Sauromyia, with two series: oswaldoi and atroclavata; Coquillettimyia Galati 1995, also with two series: vexator and chiapanensis and Micropygomyia, s. str., divided into two series: cayennensis and pilosa; beyond these subgenera, two isolated species: Mi. xerophila (Young, Brener \& Wargo, 1983) and Mi. breviducta (Barretto, 1950) were included.

According to Galati $(1995,2003 b)$ the subgenus Micropygomyia may be characterized as follows: both sexes with palpomere V longer than III, and palpomere II shorter or equal to IV; Newstead's spines grouped in the basal part of palpomere III; absence of the papilla on the antennomere $\mathrm{AV}$; ventrocervical sensillae present,

${ }^{+}$Corresponding author: egalati@usp.br

Received 3 May 2007

Accepted 4 July 2007 without setae on the anterior margin of the katepisternum. Male: post-alar setae absent; labial suture forming a fork; gonostyle with four spines, one being apical; gonocoxite with or without tuft of setae. The females present cibarium with four or more posterior (horizontal) teeth with fused base; pharynx with or without spines in its apical region. The males of the pilosa series present the lower external spine in the gonostyle atrophied; the females have a cibarium with a long and narrow chamber, in such a way that the anterior teeth are situated laterally in the greater part and the two posterior pairs are united at the base; ascoids of AIV long, their apices almost reaching the apex of the article; rudimentary common sperm duct. The males of the cayennensis series present a gonostyle with four fully developed spines and gonocoxite without tuft of setae either in the basal or in the median region; females: ascoids of AIV short, generally their apices do not reach the point of insertion of the papilla and their length is equivalent to $1 / 3$ or half of the flagellomere's length; cibarium with two or more pairs of posterior teeth.

The subgenus Helcocyrtomyia was proposed by Barretto (1962) as belonging to the genus Lutzomyia França, 1924, including the species-group: peruensis, oswaldoi, vexatrix and sanguinarius. Theodor (1965) did not accept Helcocyrtomyia, but he adopted the species-groups: oswaldoi and vexatrix; this latter he divided into the series: vexatrix and peruensis. In the series peruensis, were included the species considered by Barretto (1962) as the sanguinarius group. Lewis et al. (1977) follow Theodor (1965) and Martins et al. (1978) in adopting Barretto's (1962) proposition. Young and Duncan (1994) adopted the oswaldoi group in accordance with Theodor (1965) and Lu. (Helcocyrtomyia), though without separating it into series. Galati (1995) adopted Lu. (Helcocyrtomyia); however, the vexator and 
oswaldoi series were included in the genus Micropygomyia, the former series in the subgenus Coquillettimyia Galati, 1995, and the latter in Sauromyia. Galati and Cáceres (1994) divided Lu. (Helcocyrtomyia) into three series: sanguinaria Barretto, 1962, osornoi Galati \& Cáceres, 1994 and peruensis.

Lu. (Helcocyrtomyia) chavinensis, having as typelocality San Marcos, Huari province, Ancash department, at an altitude of $2900 \mathrm{~m}$ (Pérez \& Ogusuku 1999), in accordance with Galati (2003a), belongs to the series peruensis. The females of this series are characterized by a long clypeus, $1 / 3$ longer than the length of the head, and the palpomere IV equivalent to or longer than $2 / 3$ of the III, or with four or more pairs of setae; cibarium with four posterior horizontal teeth, spermathecae ringed with the apical ring clearly longer than the pre-apical.

The objective of this study is to present the description of a new species of the genus Micropygomyia and of the female of Lu. (Helcocyrtomyia) chavinensis.

\section{MATERIALS AND METHODS}

The specimens were clarified in accordance with Forattini (1973) and mounted on microscope slides in NC medium (Cerqueira 1943). They were measured with a Zeiss ${ }^{\circledR}$ eye-piece calibrated with a standard Zeiss ${ }^{\circledR}$ scale and drawn with the help of an Olympus ${ }^{\circledR}$ microscope.

The specimens were captured with a manual aspirator in a cave, located at $3000 \mathrm{~m}$ a.s.l. The structural terminology, generally, follows McAlpine (1981), apart from some specific structures studied in phlebotomines (ventrocervical sensillae, setae on the anterior edge of katepisternum and labial sutures) which conform to Galati's (2003b) terminology. The measurements are given in micrometers. The type-material will be deposited in the entomological collection of the Instituto Nacional de Salud (INSL), Lima, Peru.

Micropygomyia (Micropygomyia) ancashensis sp. nov. (Figs 1-9, 24)

Holotype (male) - Total body length 2793; whole insect with pale coloring.

Head (fontal view) (Fig. 1) - Length 435; width 305. Eye: length 165; width 96. Interocular distance 136. Interocular suture separated from antennal suture. Clypeus: length 174; width 122. Antennomere lengths: AIII 331, AIV 154 (Fig. 3), AV 163 (Fig. 4), AXI 140, AXII 132, AXIII-AXVI were lost. AIII/head length ratio: 0.76:1.0. Antennal formula AIII-AXII 2; ascoids simple and very short, the apices of those on AIV do not reach the middle of the segment (Fig. 3); papilla absent on AV (Fig. 4), AXI and AXII. Length of the palpomeres: I 44, II 169, III 194, IV 176, V 465. Palpal formula: 1.2.4.3.5. Newstead's spines grouped in the basal third of palpomere III (Fig. 5) and absent on palpomere II. Labrum-epipharynx 244 long. Cibarium (Fig. 2): anterior and posterior teeth not observed with 40x objective; sclerotized arch incomplete; sclerotized area of funnel shape; salivary gland highly conspicuous. Pharynx without spines. Labium with the labial sutures united only in their basal region. Labella with strong sclerotized pseudotracheae (Fig. 24).

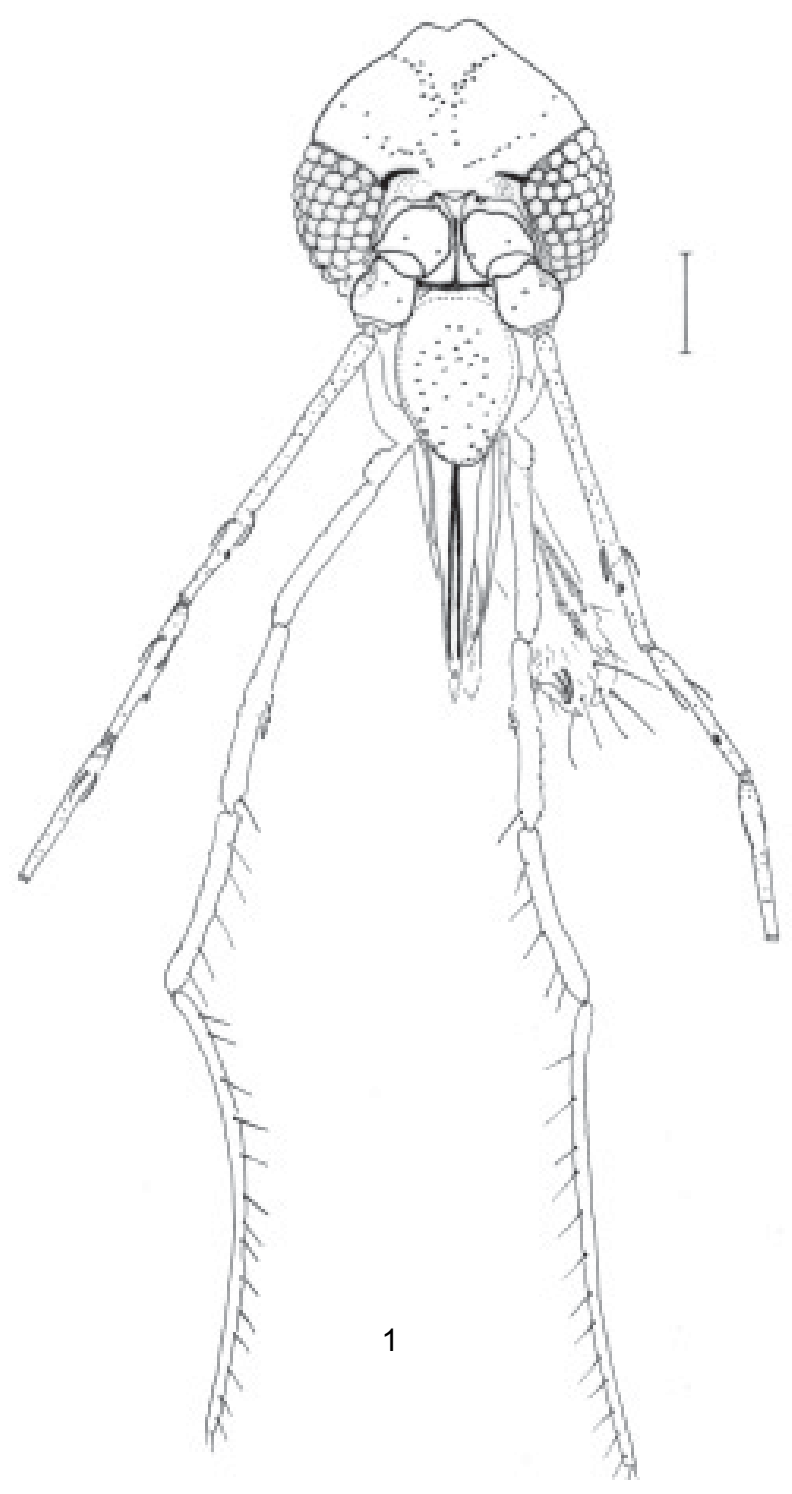

Fig. 1: head, frontal view (holotype ${ }^{\top}$ ). Micropygomyia ancashensis sp. nov. $\mathrm{Bar}=100 \mathrm{~mm}$.

Cervix - Ventrocervical sensillae present.

Thorax - Length 653. Mesonotum length 560. Pleurae with six proepimeral setae and five upper anepisternal setae; setae absent on the anterior katepisternum margin; suture between katepimeron and metepisternum absent. Wing (Fig. 6): length 2532, width 592; length of vein sections: alpha 441, beta 261 , gamma 435 , delta 61, pi 87, $\mathrm{R}_{5} 1592$. Length of femora, tibiae, basitarsi, and tarsi II+III+IV+V: foreleg 957, 1279, 766, 853; midleg 896, 1414, 835, 855; hindleg lost. The implantation of the spines on tarsomere III is made as verticiles on three levels.

Abdomen - 1705 long. Tergites VI-VII with tergal papillae. Terminalia (Fig. 8): gonostyle 128 long, with four spines with the following disposition: one apical, 

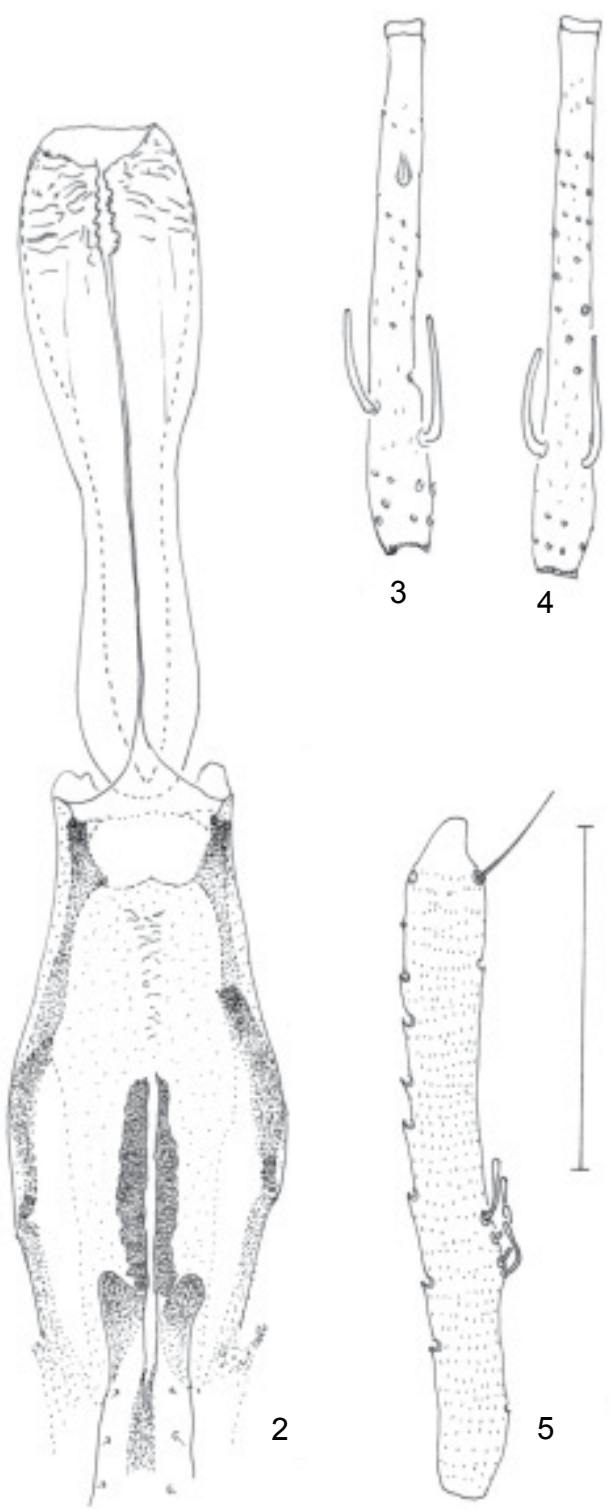

Figs 2-5: Micropygomyia ancashensis sp. nov. (holotype $0^{\top}$ ). 2: cibarium and pharynx; 3: AIV; 4: AV; 5: palpomere III. Bar $=100 \mathrm{~mm}$.

the upper external subapical, the lower external slightly beyond the middle and the internal one implanted in the middle; gonocoxite 202 long $\times 55$ wide, without setae; paramere simple, dorsal margin 154 long, the basal half rectangular without setae and the apical half tapering and covered with thin setae; conical aedeagus: dorsal margin length 119; lateral lobe: length 200; width 24; cercus 173 long. Genital pump 132 long; piston length 110; pavilion width 26; chamber width 40 ; genital filaments length 550 or 4.17 times the length of the genital pump. Tip of genital filaments simple and truncated (Fig. 7).

Type-material - Holotype male. PERU, Department of Ancash, Antonio Raymondi province, Chingas district, in cave located at $3000 \mathrm{~m}$ a.s.l., captured with manual aspirator, 7 Jun 1999, 8:00 h, Cáceres AG col.
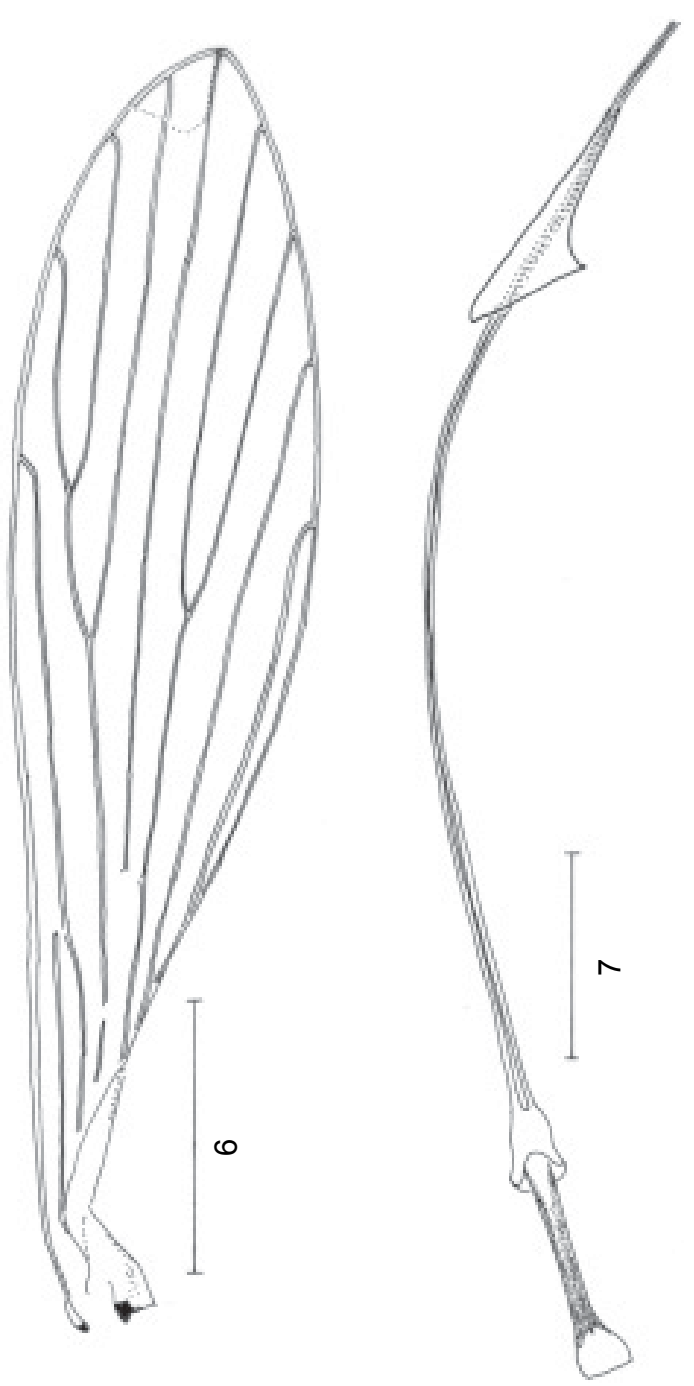

Figs 6-7: Micropygomyia ancashensis sp. nov. (holotype ơ). 6: wing (bar $=500 \mathrm{~mm}) ; 7$ : ejaculatory pump and ducts $($ bar $=100 \mathrm{~mm})$.

The Mi. ancashensis species was thus named in allusion to the department in which the specimen was captured.

Lutzomyia (Helcocyrtomyia) chavinensis Pérez \& Ogusuku, 1999

(Figs 10-23)

Female - Total body length about 3448 . General coloration light brown.

Head (Fig. 10) - Length 518; width 348. Eye: length 113; width 95. Interocular suture separated from antennal suture. Interocular distance 180. Clypeus: 196 long; width 117. Flagellomeres: AIII 392, AIV 176 (Fig. 11), AV 169 (Fig. 12), AXI 138, AXII, 130, AXIII 120 (Fig. 13), AXIV 80 (Fig. 14), AXV 70 (Fig. 15), AXVI 75 (Fig. 16). AIII/head length ratio: 0.76:1.0. Antennal formula: AIII-AXV 2, XVI 0. Ascoids simple, apices of those on AIV go slightly beyond the middle of the article (Fig. 


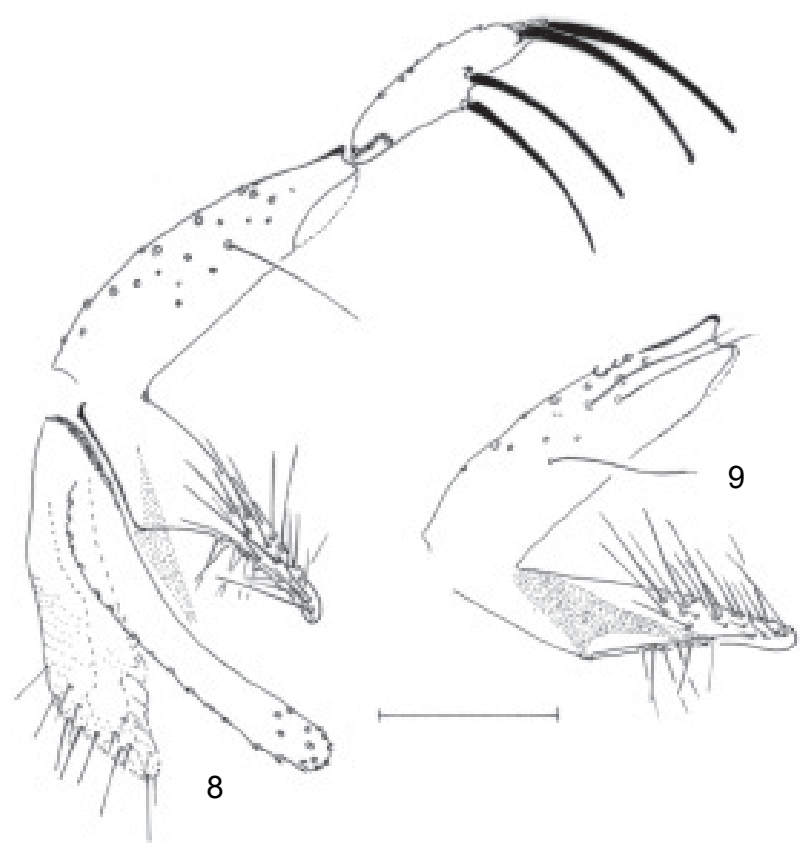

Figs 8-9: Micropygomyia ancashensis sp. nov. (holotype o). 8: terminalia; 9: the other gonocoxite, paramere, and aedeagus. Bar $=100 \mathrm{~mm}$.

11). Papilla present on AV (Fig. 12). Palpomere length: I 35, II 187, III 220, IV 165, V 470. Palpal formula: 1.4.2.3.5. Newstead's spines grouped in the median third of palpomere III (Fig.17). Labrum-epipharynx (Fig. 18) 365 long. Cibarium (Fig. 22): presence of four posterior needle-like horizontal teeth set into a clear monticle; presence of eight greatly reduced anterior teeth, disposed in a transversal row; the posterior bulge is conspicuous and the sclerotized area narrow and long; lateral teeth not observed with 40x objective; arch incompletely sclerotized. Pharynx without conspicuous spines in its apical region. Hypopharynx (Fig. 19) with about 18 welldelineated apicolateral teeth. Maxilla: lacinia with about six external teeth disposed in a longitudinal row and 23 internal teeth (Fig. 20).

Cervix - ventrocervical sensillae present.

Thorax - Length 780. Mesonotum 680 long. Pleurae with two proepimeral setae, 11 upper anepisternal setae; setae absent on the anterior katepisternum margin; suture between katepimeron and metepisternum absent. Wing (Fig. 21): length 2993, width 810; length of vein sections: alpha 610, 670, beta 375, 390, gamma 557, 560, delta 100, 150, pi 50, 70, R5 1960, 1980. Length of femora, tibiae, basitarsi, and tarsi II $+\mathrm{III}+\mathrm{IV}+\mathrm{V}$ : foreleg 1018, 1253, 870, 943; midleg 983, 1548, 948, 957; hindleg 1088, 1827, 1218, 1108.

Abdomen - Length 2150. Tergite VIII with nine or 10 setae on each side. Spermathecae (Fig. 23) 28 long and 12 at maximum width; with about 11 rings, the apical longer than and as wide as the preapical one; individual sperm ducts 210 long $\times$ five wide in the median part and

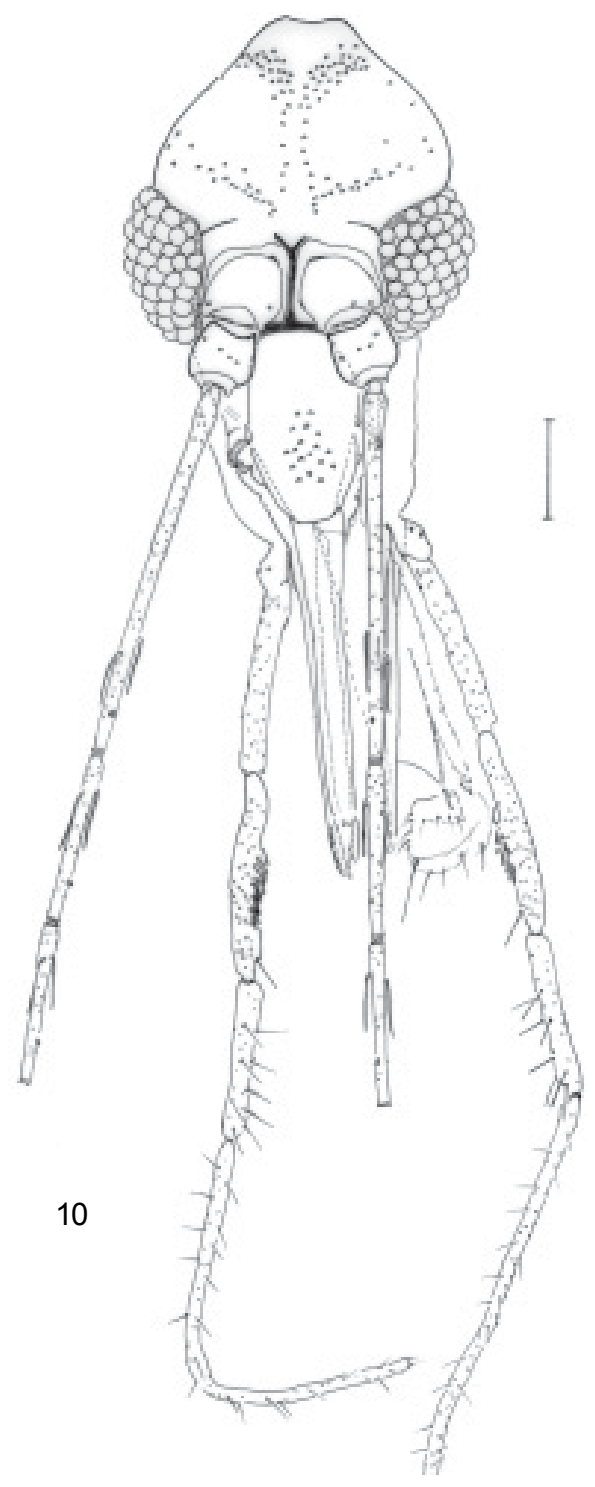

Fig. 10: Lutzomyia chavinensis $($ ( ) head. $\mathrm{Bar}=100 \mathrm{~mm}$.

6.8 at the junction with the spermathecae; common sperm duct membranous, smooth and short, width at its insertion 11, the length was impossible to measure; terminal knob individualized. Cercus 158 long.

Material examined - one female: PERU, Ancash department, Antonio Raymondi province, Chingas district, in cave located at $3000 \mathrm{~m}$ a.s.1., captured with manual aspirator 7 Jun 1999, Cáceres AG col.

\section{TAXONOMIC DISCUSSION}

The morphological characteristics described for $M i$. (Mi.) ancashensis sp. nov.: gonostyle with four fully developed spines; gonocoxite without tuft of setae and paramere simple permit its inclusion in the cayennensis series which is constituted by 12 species and the $M i$. cayennensis complex of eight subspecies, with the re- 

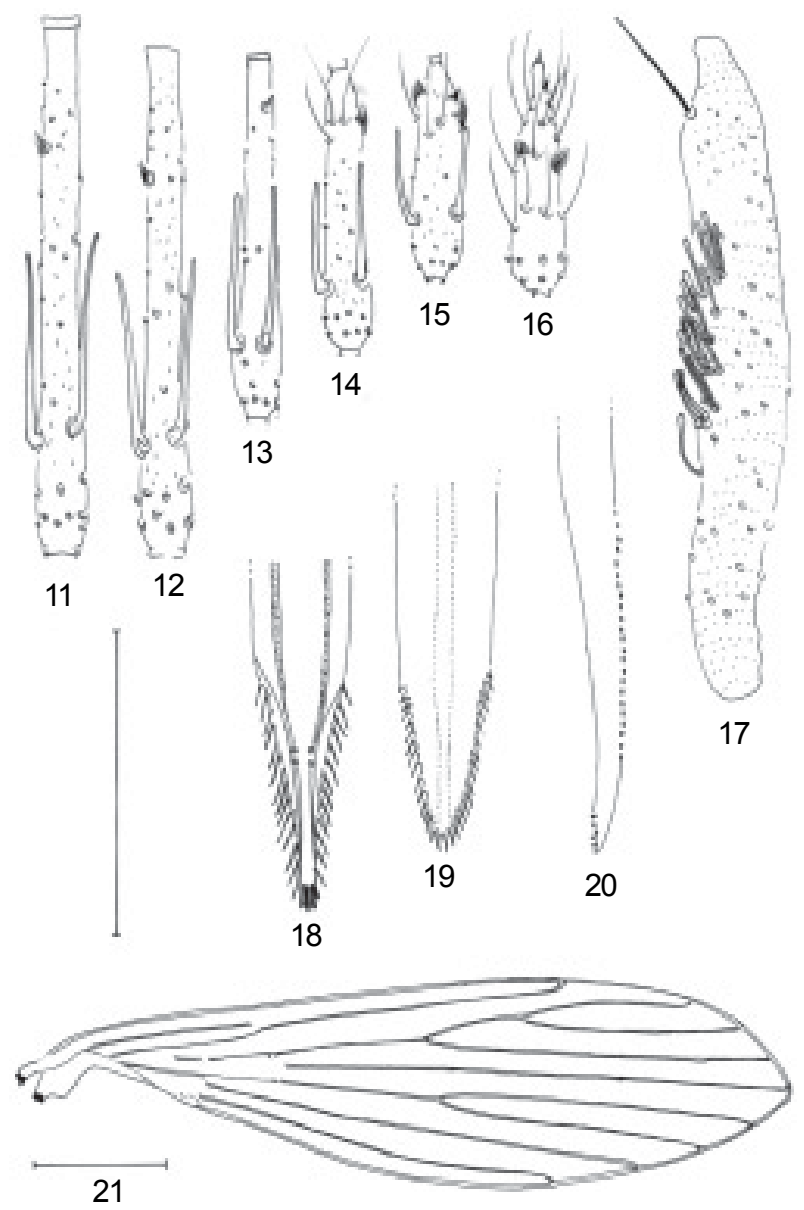

Figs 11-21: Lutzomyia chavinensis ( ). 11: AIV; 12: AV; 13: AXIII, 14: AXIV; 15: AXV; 16: AXVI; 17: palpomere III; 18: labrum-epipharynx; 19: hypopharynx; 20: lacinia of the maxilla; 21: wing. Bars: wing $=500 \mathrm{~mm}$ and the other figures $=100 \mathrm{~mm}$.

spective sex described: Mi. absonodonta (Feliciangeli, 1995) (우), Mi. cayennensis cayennensis (Floch \& Abonnenc, 1941) ( $\sigma^{\top}+$ ), Mi. cayennensis braci (Lewis, 1967) (ơ ㅇ), Mi. cayennensis cruzi (Gonzales \& Garcia, 1981) (ơ o), Mi. cayennensis hispaniolae (Fairchild \& Trapido, 1950) (oㅇ ), Mi. cayennensis jamaicensis (Fairchild \& Trapido, 1950) ( ๑ ㅇ ), Mi. cayennensis maciasi (Fairchild \& Hertig, 1948) ( $0^{\circ}$ \%), Mi. cayennensis puertoricensis (Fairchild \& Hertig, 1948) (o o f), Mi. cayennensis viequesensis (Fairchild \& Hertig, 1948) ( $0^{\top}$ \%), Mi. ctenidophora (Fairchild \& Hertig, 1948) (ㅇ), Mi. cubensis (Fairchild \& Trapido, 1950) ( $0^{\star}$ ㅇ), Mi. duppyorum (Fairchild \& Trapido, 1950) (o (Vargas \& Diaz-Nájera, 1952) (o + + ), Mi. farilli (Vargas \& Diaz-Nájera, 1959) (†), Mi. hardisoni (Vargas \& DiazNájera, 1952) (ơ +), Mi. lewisi (Feliciangeli, Ordoñez \& Férnandez, 1984) (ơ + ), Mi. micropyga (Mangabeira, 1942) (o + ), Mi. schreiberi (Martins, Falcão \& Silva, 1975) ( ○ + ), Mi. wirthi (Vargas \& Dias-Nájera, 1951) (ㅇ) and Mi. yencanensis (Ortiz, 1965) (o $\%$ ).

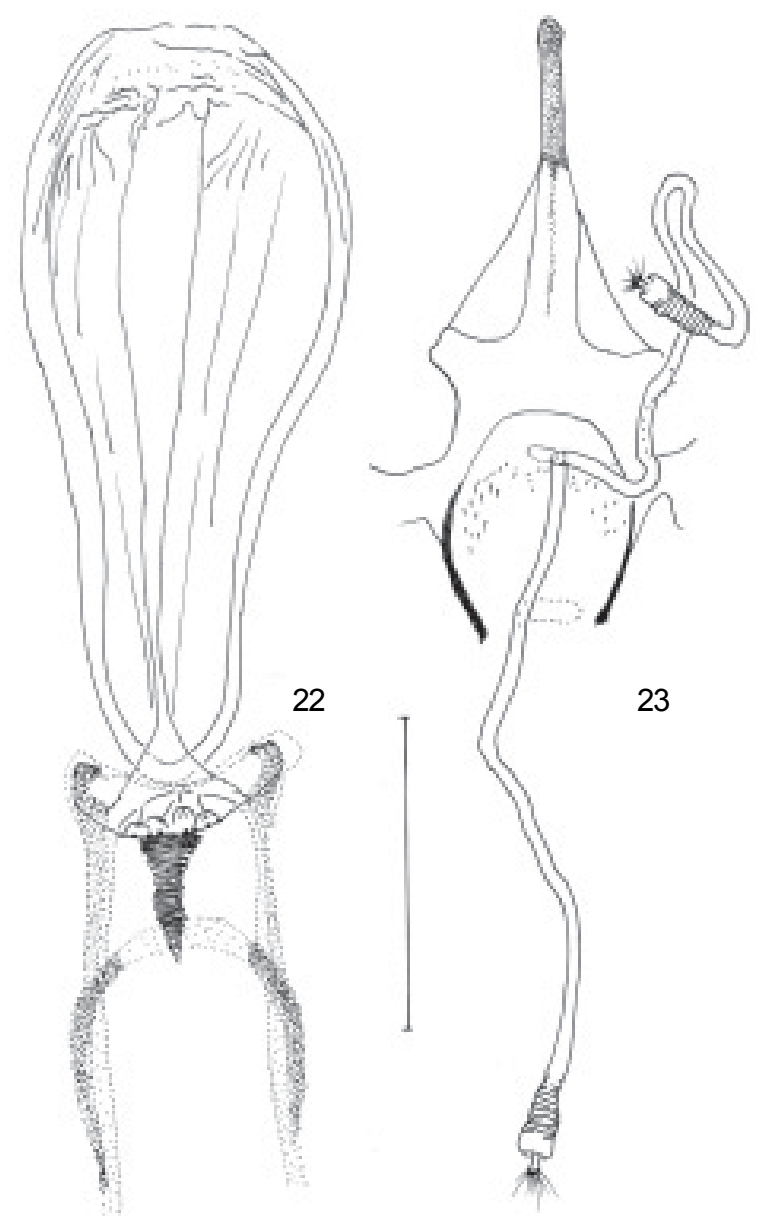

Figs 22-23: Lutzomyia chavinensis ( + ). 22: cibarium; 23: spermathecae and genital furca. $\mathrm{Bar}=100 \mathrm{~mm}$.

The pale coloration of the scutum of this new taxon distinguishes it from the other taxa of the cayennensis series, except for Mi. lewisi. However, there are various differences between the two species: the ratio between the length of the genital ducts/genital pump is smaller in the new species (4.17:1.0) than in Mi. lewisi (5.0:1.0); the palpus is much longer in the new species $(1048 \mathrm{~mm})$ while in Mi. lewisi its maximum value is $764 \mathrm{~mm}$ (Feliciangeli. 1995); and the tip of the genital filament is not enlarged in the new species, whereas it is in Mi. lewisi.

The presence of sclerotized pseudotracheae on the labella (Fig. 24) of this new taxon seems to be an autapomorphy in this species, seeing that we never find this sclerotinization in other species, at least, among American phlebotomine fauna. On the other hand, one characteristic in the plesiomorphic state, the clypeus practically completely covered with setae, present in this new species has otherwise only been observed among American sandflies in Warileya. Further, tarsomere III of this new taxon with the spines implanted in verticiles 


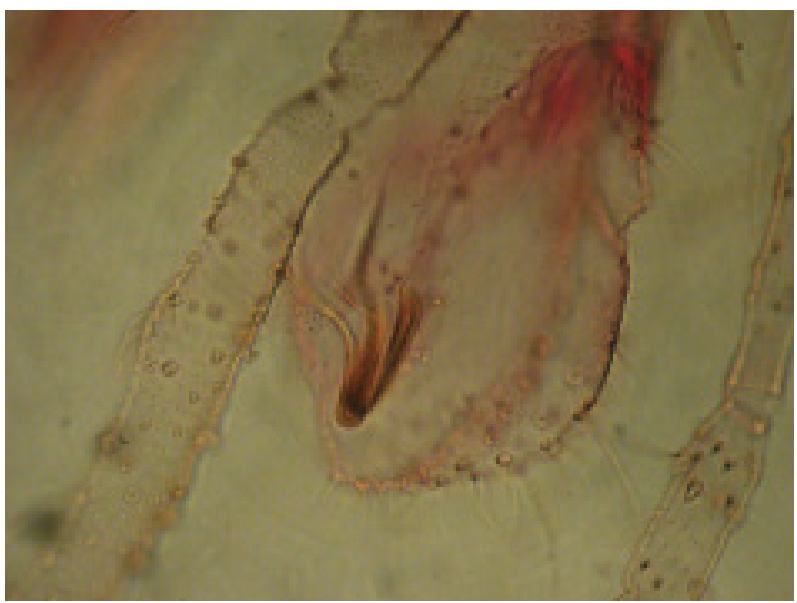

Fig. 24. Micropygomyia ancashensis sp. nov. (holotype ơ). Labella with strong sclerotized pseudotracheae.

at three levels, at least on the foreleg and midleg (the hindlegs were lost) is also infrequent among Micropygomyia. Thus this new taxon presents various characteristics that distinguish it from the species of Micropygomyia and also of other groups of phlebotomines. As regards the female described the suspicion that justifies its inclusion in Lu. (Helcocyrtomyia) chavinensis is based on: its capture together with two males of that species, whose type-locality is the Ancash department (2900 $\mathrm{m})$; the absence of setae on the anterior margin of the katepisternum, the very short delta/alpha alar index $(0.16-0.22)$ and the general coloration, as in the male.

In the peruensis series, the absence of setae on the anterior margin of the katepisternum occurs as well as in Lu. chavinensis, in Lu. noguchii (Shannon, 1929), Lu. blancasi Galati \& Cáceres, 1990, and Lu. pallidithorax Galati \& Cáceres 1994.

The presumed female of Lu. chavinensis is distinguished from that of $L u$. pallidithorax by having a clypeus longer than the eye and a smaller delta (about $1 / 6$ of alpha), whereas in this latter species the clypeus is shorter than the eye and delta is about $1 / 3$ of alpha; from $L u$. noguchii, by the greater length of AIII and the labrum-epipharynx (392 $\mathrm{mm}$ and $365 \mathrm{~mm}$, respectively) which in this species are smaller than $300 \mathrm{~mm}$; from $\mathrm{Lu}$. blancasi by the shorter antennomeres of this latter species (AIII $324 \pm 19 \mathrm{~mm}$; AIV $147 \pm 7 \mathrm{~mm}$; $\mathrm{n}=10$ ) (Galati \& Cáceres, 1990) and by the posterior teeth of $\mathrm{Lu}$. chavinensis which are implanted in monticles, differently from $L u$. blancasi.

\section{ACKNOWLEDGEMENTS}

To Dr Percy Minaya León, Director of the Oficina de Epidemiología, Ministry of Health of the Peru, by the coordination with the authorities of the Health Center of Chingas, to make an evaluation and entomological inventory of the phlebotomine fauna of the Chingas district, Antonio Raymondi province, Ancash department.

\section{REFERENCES}

Artemiev MM 1991. A classification of the subfamily Phlebotominae. Parassitologia 33(Supl. 1): 69-77.

Barretto MP 1962. Novos subgêneros de Lutzomyia França, 1924 (Diptera, Psychodidae, subfamília Phlebotominae). Rev Inst Med Trop São Paulo 4: 91-100.

Cerqueira NL 1943. Novo meio para montagem de pequenos insetos em lâminas. Mem Inst Oswaldo Cruz 39: 37-41.

Feliciangeli MD 1995. Phlebotomine sandflies in Venezuela. IV. Review of the Lutzomyia subgenus Micropygomyia (Diptera: Psychodidae), with the description of L. absonodonta n. sp. and the male of L. lewisi. Ann Trop Med Parasit 89: 551-567.

Forattini OP 1973. Entomologia Médica. Psychodidae. Phlebotominae. Leishmanioses. Bartonelose, Edgard Blücher/ EDUSP, São Paulo, 658 pp.

Galati EAB 1995. Phylogenetic systematics of Phlebotominae (Diptera, Psychodidae) with emphasis on American groups. Bol Dir Malariol Saneam Amb 35 (Supl. 1): 133-142.

Galati EAB 2003a. Classificação de Phlebotominae. In EF Rangel, R Lainson, Flebotomíneos do Brasil, Fiocruz, Rio de Janeiro, p. 23-51.

Galati EAB 2003b. Morfologia, terminologia de adultos e identificação dos táxons da América. In EF Rangel, R Lainson, Flebotomíneos do Brasil, Fiocruz, Rio de Janeiro, p. 53-175.

Galati EAB, Cáceres AG 1990. Descrição de Lutzomyia blancasi, sp. n. e Lutzomyia tejadai, sp. n. (Diptera, Psychodidae, Phlebotominae) dos Andes peruanos. Rev Bras Ent 34: 505-521.

Galati EAB, Cáceres AG 1994. Descrição de Lutzomyia pallidithorax, sp. n. e Lutzomyia castanea, sp. n. do Peru e análise cladística das séries do subgênero Helcocyrtomyia Barretto (Diptera, Psychodidae, Phlebotominae) Rev Bras Ent 38: 471-488.

Lewis DJ, Young DG, Fairchild GB, Minter DM 1977. Proposals for a stable classification of the Phlebotominae sandflies (Diptera: Psychodidae). System Ent 2: 319-32.

Martins AV, Williams P, Falcão AL 1978. American Sand Flies (Diptera: Psychodidae, Phlebotominae), Academia Brasileira de Ciências, Rio de Janeiro, 195 pp.

McAlpine J F 1981. Morphology and terminology - Adults. In JF McAlpine, BV Peterson, GE Shewell, HJ Teskey, JR Vockeroth, DM Wood, Manual of Nearctic Diptera, Monography 27, Vol. 1. Research Branch Agriculture Canada, Ottawa, p. 9-63.

Pérez E, Ogusuku E 1999. Descripción de Lutzomyia chavinensis sp. n. (Diptera: Psychodidae) del Departamento de Ancash, Peru. Rev Per Ent 41: 53-56.

Theodor O 1965. On the classification of the American Phlebotominae. J Med Entomol 2: 171-197.

Young DG, Duncan MA 1994. Guide to the identification and geographic distribution of Lutzomyia sand flies in Mexico, the West Indies, Central and South America (Diptera: Psychodidae). Mem Amer Entomol Inst 54: 1-881. 